\section{LA FORMACIÓN SACERDOTAL HACIA EL TERCER MILENIO}

Autor: Ricardo Cuéllar Romo. Ex rector del Colegio Mexicano de Roma Secretario Adjunto del CELAM. Roma Julio 1999.
Teniendo como trasfondo los últimos documentos de la Iglesia sobre formación sacerdotal y partiendo de la propia experiencia, Ricardo Cuéllar quiere proporcionarnos pistas concretas sobre la formación abierta al futuro que él concreta en tres ángulos: el servicio, la comunión, el testimonio. El servicio en vistas al ministerio que ha de desempeñar, la comunión que le abra al obispo, el presbiterio y los fieles y el testimonio en fidelidad al ser pastor dentro de la Iglesia.

DOI: https://doi.org/10.52039/seminarios.v46i156.1056

\title{
INTRODUCCIÓN
}

Este no es un estudio teórico, sino una aportación desde mi experiencia de trabajo en organismos e instituciones íntimamente ligados a la formación sacerdotal.

Es una aportación que tiene como telón de fondo los siguientes documentos: LG, OT, PO, PDV, Puebla, Santo Domingo, RFIS.

Parto de este presupuesto: los procesos, los métodos, las propuestas formativas en un seminario Diocesano tienen como punto de referencia inmediata la Iglesia Particular. Hay una conciencia más o menos explícita de formar para una determinada Diócesis. Los recursos, la orientación de las líneas formativas, la sensibilidad primera, etc. se orientan a la práctica pastoral en un ambiente directo, muchas veces 
parroquial. De ahí que el marco de esta reflexión sea eclesiológico concreto: la Diócesis, un Obispo, el presbiterio, la caridad pastoral.

Propongo este estudio en tres partes, que serían como tres ángulos del marco eclesiólogico en el que se inspira esta intervención. No se agota aquí la reflexión eclesiológica que puede iluminar una propuesta formativa global; muchos filones interesantes se tienen que dejar a un lado. Por otra parte, lo que se propone aquí tiene la pretención de validez para proyectos de formación, se trate de la formación en el seminario o de la formación en el presbiterio.

En cada uno de los ángulos propongo este esquema: selección de un valor en algún punto central del aspecto eclesiológico en turno; unas líneas que pueden inspirar los proyectos formativos; algunas sugerencias a los formadores de Seminarios, para crear actitudes en los formandos.

\section{PRIMER ÁNGULO: EL SERVICIO}

Seminarista, o joven creyente en vistas a una misión

\section{1.- VALOR SELECCIONADO: SERVICIO A LA PALABRA Y AL PUEBLO}

Para individuar el perfil HUMANO Y ESPIRITUAL del sacerdote diocesano, desde el valor del servicio a la Palabra y al pueblo que le es confiado, indico dos rasgos centrales. No son los únicos, pero los considero fundamentales y válidos tanto en la etapa de formación seminarística como en la formación continuada del presbítero. Podrían servir, también, como una sugerencia-propuesta formativa.

El seminarista diocesano es:

Un joven-creyente comprometido en su formación integral.

Que se encuentra en el Seminario, en vistas de una misión.

En estas dos vertientes se pueden diseñar algunas características de propuesta formativa.

I.- El compromiso de formación integral es un terreno muy basto. Ahora yo me fijaré más en el terreno del estudio, porque me parece que el avance en la consolidación de la personalidad de un joven seminarista que estudia filosofía o teología, depende, en gran 
parte, de las ideas claras que tenga, sobre Dios, la Iglesia, el hombre, el mundo. Continuamente será dicho y propuesto el valor de una formación integral, armónica, gradual, progresiva, etc., pero el hecho es que un buen porcentaje de la vida de un joven en el seminario se dedica a la reflexión, al estudio, al análisis, a la meditación...

Se ha de educar en una coherente generosidad para afrontar el cansancio cotidiano del estudio como verdadera ascesis. El modo como se estudia, el estilo de vida que se requiere (silencio, relativa soledad, dedicación, concentración), el ejercicio de la inteligencia en la búsqueda de la Verdad, constituyen, ya y de por sí, una escuela de santidad y un testimonio de amor cristiano. Hoy, nuestros jóvenes viven en un mundo que ha fragmentado mucho los conocimientos, un mundo dominado por la noticia desechable, inmerso en la imagen, más afanado por lo que gusta y da satisfacción que por lo verdadero, por ello es necesario precisar este valor y darle toda la importancia que requiere.

Sin embargo, el estudio filosófico-teológico-eclesial de un joven seminarista se ha de colocar en el horizonte de una serie de valores en equilibrio que garanticen la calidad cristiana del mismo e impidan su degradación. Enumero algunos acentos que me parecen relevantes:

Entre más se profundice en la reflexión de la fe y el conocimiento teológico del misterio, más se hace importante la solidez de la vida interior, la capacidad contemplativa, la experiencia propiamente espiritual; de otra manera el estudio se vuelve árido y se "intelectualiza" la fe en sentido negativo. Sin perder nada de su carácter científico, la teología debe ser tal que brote de la fe y nutra la fe. La Iglesia espera teólogos, filósofos, liturgistas, canonistas, pastoralistas, etc. que no sean sólo predicadores y expositores, quizá brillantes, de la Palabra, sino hombres capaces de guiar hacia Cristo y de encarnar en su vida la sabiduría y santidad del único Maestro de todos; éste es el servicio típico de un sacerdote diocesano.

Entre más se ocupe uno de cuestiones especulativas y abstractas, más es necesario educarse en el sentido de lo concreto. La experiencia prolongada de 7 años de estudio en el seminario quizá logre capacitar para individuar la forma ideal de solución a los problemas, y más aún, se llega a poner, teóricamente, el dedo en las raíces últimas de los mismos; si esto no va acompañado de un sincero esfuerzo por

Profundizar en la reflexión de la fe da solidez a la vida interior

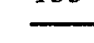


asimilar madura y pacientemente la sacramentalidad de las mediaciones humanas, por el análisis objetivo de lo complejo de algunas situaciones, por la aceptación serena de la fragilidad humana y de la diversidad de los caminos reales de las personas... entonces, la ventaja teórica de un serio estudio de la filosofía y de la teología podrían llegar a ser una pérdida total de eficacia para la vida de la Iglesia, o al menos, un inútil ejercicio formal intelectual. Muchas crisis sacerdotales han tenido su raíz en este punto.

Si pensamos en la formación permanente, lo anterior sigue siendo una exigencia, porque, en la medida que se avanza en el estudio y la reflexión, es inevitable la especialización más restringida y profundizada. Pero no es posible la especialización auténtica sin el dominio de las categorías teológicas fundamentales y sin una visión de síntesis, lo cual se ha de lograr en el Seminario. Desgraciadamente, hoy el saber teológico se ha fragmentado mucho y hemos visto cómo se multiplican los "cursitos"; las mismas Universidades, a veces, parecen supermercados a los que se va para seleccionar los "artículos" que, por su presentación (títulos, simpatías con los profesores, gustos personales, etc.) atraigan a más "clientes". Se podrá servir a la Palabra y al Pueblo en la medida de las seguridades conceptuales que se tengan; sin esto todo se relativiza y desmorona.

Especiali zarse sin perder de vista el sentido del conjunto
El proceso de especialización, por otro lado, es fundamentalmente sano; además es necesario, cada vez más, por el alto grado de complejidad en los estudios teológicos, pero ello debe ser compensado con una, cada vez mayor, atención al sentido del conjunto, a la interdisciplinariedad, al espíritu de colaboración y de condivisión, a la "circulación" fraterna de las propias competencias; especialización no quiere decir autonomía ni autosuficiencia, bajo pena de aislamiento de cada "experto" en su propia torre de marfil.

Quien trabaja seriamente en torno al estudio de la fe no se puede contentar con promover el máximo rigor en la investigación y la máxima coherencia en el procedimiento científico; tales valores, ciertamente, son irrenunciables y en sí mismos educativos. Pero van unidos a la pasión y al gusto por la transparencia en la comunicación, a la sencillez en el discurso, a la "competencia" pedagógica propia de un pastor, que no piensa ir -en primer término- a las aulas universitarias sino al pueblo concreto de una parroquia de su diócesis. La pre- 
ocupación por hacer una apasionada búsqueda de la verdad no significa ninguna rareza ni en el lenguaje, ni en la conducta, ni en el estilo de vida; al contrario, la investigación pura (tanto más el ministerio de la docencia, y el cotidiano ministerio de la palabra en la predicación y en el contacto ordinario con los fieles) logrará atraer más en base a su claridad y sencillez, y a la "fascinación" propia de la verdad.

II.- El joven seminarista se prepara, integralmente, en vista de un ministerio eclesial que le será confiado.

También en esta prospectiva se pueden individuar algunos acentos específicos formativos.

Es casi inevitable que el hecho de ser seminarista-sacerdote, se perciba como un don de predilección de parte de Dios. Sin discutir lo anterior, se ha de acentuar tal hecho como una llamada al servicio de donación total, hasta la cruz, por los hermanos. Muchas veces las realidades sociales y aún las meramente personales impulsan a entender la predilección de Dios, como un privilegio respecto a la condición de los propios hermanos, jóvenes o adultos de la Diócesis. Frente a esta sensación surge, normalmente, en los formadores y también en los alumnos, un sano rechazo de la tentación del privilegio. A veces, incluso, se exagera, ocultando o perdiendo toda referencia a las convenciones sociales, a la buena educación, etc., o asumiendo posturas de desprecio, -o al menos de distanciamiento- hacia "formas y lógicas" inevitables en la convivencia humana.

Sin embargo la tentación de ser el elegido, de sentirse el mejor, del privilegio, etc. a veces se deja entrever con reclamos, exigencias y pretensiones, que impiden verificar, en los hechos, la disponibilidad al servicio desinteresado. Un catalizador de lo anterior se suele dar cuando se trata de poner a prueba, en circunstancias difíciles, la disponibilidad y el servicio concreto a la Iglesia local y al Obispo, cuando hay que incorporarse al tejido vivo de la colaboración pastoral en el presbiterio. Por este motivo, el descubrimiento, la percepción serena de los propios talentos y su consolidación, deben caminar al mismo ritmo que se crece en una decidida y generosa voluntad de servir, de poner a disposición de la Diócesis, el propio ser y todo lo que se ha adquirido en el Seminario, en el lugar y trabajo que le será asignado por quien, por propio

No caer en la tentación de considerarse 'el elegido' 
deber, considere más oportuno para el bien de la Iglesia Diocesana o, incluso, supradiocesana en sus diferentes niveles. Esta dimensión de servicio de la vida cristiana del seminarista y sacerdote es importante y no será exagerado reclamarla, diariamente, no tanto con palabras sino con gestos y servicios simples, condivididos generosamente.

Para favorecer la formación honda, integral, en el Seminario se necesita poner una cierta distancia del tumulto de las cosas y compromisos, una cierta libertad de los afanes de mil preocupaciones. Mientras se cuida este aspecto, se deberá evitar, de todos modos, vivir "en la cápsula" de protección de la condición seminarística estudiantil. Será necesario, en otros términos, estar atentos y participar, también, en los afanes reales de la gente; saber resonar interiormente delante de los acontecimientos pequeños y grandes de la Iglesia y de la sociedad civil, permanecer abiertos y "vulnerables" en relación a los sufrimientos de los hermanos. El clima de "reserva y protección" en el cual

Participar en los afanes reales de la gente se ha de vivir en el Seminario no puede traducirse en indiferencia o impasibilidad, como si la vida y realidad que circunda fuera una distracción peligrosa para la formación en el Seminario.

Un alumno de un Seminario goza de gran disponibilidad de tiempo. Si comparamos con la vida de otros jóvenes estudiantes o que trabajan, si comparamos con la misma vida pastoral de los presbíteros en la Diócesis, cualquiera sea el ministerio confiado, los años del Seminario son un oasis singular de tiempo disponible; esta disponibilidad es una riqueza incalculable, que deberá ser rescatada del secularismo mundano, que muchas veces propone "éxitos antievangélicos" (demasiada TV, superexpertos en navegación internet, atención exclusiva a "lo que me gusta", perezas o tiempo perdido en pláticas de café, afán morboso de estar al corriente del último "chisme" etc.), mediante una coherente dedicación, sin descuentos ni fugas, al deber cotidiano (oración, estudio, vida comunitaria en la que hay servicios, fraternidad, descanso, etc.). Creo que, concretamente, este es el camino maestro de un seminarista y de un sacerdote, para vivir y testimoniar la pobreza evangélica.

Los años de preparación son también, para un seminarista, años de experiencia de vida común como escuela de capacitación práctica para vivir la fraternidad sacerdotal. Es verdad que las condiciones de la comunidad de un seminario son irrepetibles y, por ello, la vida del 
presbítero diocesano será ciertamente muy distinta en su dimensión comunitaria, en relación al estilo concreto como se vive en un Seminario; sin embargo es verdad, también, que esta dimensión es imprescindible en la espiritualidad del sacerdote diocesano y que es condición para el servicio a la comunidad parroquial, que justifica su razón de ser. Es cierto, así mismo, que la experiencia de una auténtica fraternidad es uno de los valores más preciosos que pueden cultivarse en el Seminario; con tal que la comunidad no sea tolerada como un peso o un mal menor, o se pretenda hacer según el gusto de cada uno, o se soporte como una realidad "de paso".

Se ha de intentar, con asiduidad y fantasía, tener muy en alto un estilo de vida comunitaria como espacio de crecimiento en la filiación divina y en la fraternidad sacerdotal, que excluya los meros formulismos, que no acepte una adhesión pasiva por conveniencias personales, que no se contente con superficiales modos de "buena educación"; sino que, al mismo tiempo, cultive y propicie relaciones interpersonales profundas, auténticas, libres, educadas, respetuosas, atentas; es necesario llegar, incluso, a la solicitud por la vida del compañero, y los detalles de la casa.

El servicio al que nos formamos constantemente, está condicionado por la importancia que demos a esta dimensión comunitaria, sea seminarística o presbiteral. La comunidad es percibida no como un mero instrumento o una mediación de algunos bienes concretos, ni como algo que puede ser aprovechado para beneficios pragmáticos $\mathrm{y}$ ventajas meramente personales.

Se ve en la comunidad un gran don de profundo valor que hay que acoger con atención, cotidianamente redescubierto y vivido, como una ocasión para experimentar la bendición de la comunidad que vive el estilo de vida apostólica conglutinada en torno a Jesús, para aprender a amar bien, a hacerse querer de modo justo, a vivir como hermanos, a cultivar maduras y profundas amistades. Este es el servicio señero que un sacerdote ha de ofrecer a la Palabra y al Pueblo.

\section{2.- LINEAS INSPIRADORAS:}

1) Creyente con vosotros, ministro de fe para vosotros. Así se definía S.Agustín en relación a la comunidad que servía. Su adhesión

Cultivar la experiencia de auténtica fraternidad 
a la Palabra se traducía en el servicio a la fe de los hermanos que le había sido confiados. Esta es la "forma" específica que se ha de asumir por aquellos que se dedican al ministerio eclesial. El servicio a la Palabra y al pueblo es el fundamento y guía de la identidad misma de su vocación.

Para trazar los caminos "espirituales" de la formación inicial y permanente de un sacerdote diocesano es necesario examinar este problema: ¿cómo pueden integrarse en la vida del sacerdote una fe que ha de caminar, humildemente, al lado de las pruebas de la fe de cualquier persona y al mismo tiempo una fe tan fuerte que sepa suscitar, sostener y acompañar, con autoridad, la fe de los demás?

2) Se trata de una formación continuada, siempre, de la fe. Es un itinerario hasta la muerte. El sacerdote es un hombre que se siente llamado a vivir en la convicción de que toda la vida adquiere sentido, sólo, en Cristo Salvador. Para poder estar al servicio de la fe de los demás, necesita conocer y tener experiencia de las pruebas de la fe. Si la fe no es una abstracta adhesión intelectual a fórmulas, ni se traduce en una pasiva y habitual ejecución de "reglas" religiosas; y si por el contrario nace del encuentro vivo con Jesucristo y su Evangelio y se expresa en un compromiso de coherencia y de comunión con Él, no es de extrañar que ello comporte una difícil tarea que pone a prueba la inteligencia y la fantasía creativa: el que cree en serio es lanzado a una aventura continua que consiste en dar testimonio de la verdad del Evangelio, mostrando que éste funciona en la vida normal de un hombre normal, y lo salva. "Normal" no quiere decir fácil: en la fe se implican todos los problemas, las dificultades, las preguntas sobre el sentido de la vida, que se agolpan en los corazones humanos. Quien cree seriamente sabe bien que la fe no es un recetario de soluciones fáciles. No se trata de encontrar en ella refugio a los problemas, a buen precio. Es, más bien, una tarea a realizar. Una fe fácil difícilmente será verdadera.

3) El sacerdote, por su formación teológica y por su dedicación a las "cosas de Dios", está, particularmente, expuesto a la tentación de considerar la fe como una pacífica posesión. Así, corre el peligro de ser un testigo poco creíble para la fe de los fieles. Corre el peligro de desalentar a los hermanos que acuden a él buscando apoyo de su fe, 
pues no reconocen en él las propias dificultades que ellos encuentran en su seguimiento de Jesús. No se trata de complicar artificialmente lo que para el sacerdote puede ser simple; se trata sólo de ser honestos con Jesús y consigo mismo, sin esconderse en subterfugios de aparente consistencia, para aparecer ajenos al largo y penoso itinerario de fe que cualquier creyente auténtico debe recorrer. "Cuando las personas se acercan al sacerdote para pedirle un consejo o para confiarle sus dificultades, esperan no una simple respuesta de buen sentido, sino una palabra de fe. Quedan defraudadas cuando no encuentran en él una actitud de fe. Al contrario, cuando reconocen en él un testigo de la fe, se sienten confortados en sus convicciones" (Angelus, 17.12.89).

4) Se ha de alimentar la fe. En este terreno no se puede capitalizar para siempre ni vivir de rentas o réditos. Por ser algo vivo es necesario, absoluta y continuamente, nutrirla, protegerla y desarrollarla. Si no se cuida este aspecto lo menos que puede pasar es reducirla a una sobrevivencia sin vigor contagiante ni capacidad de fuego. Si no hay una profunda experiencia de fe, ni se sirve a la Palabra ni al Pueblo. Y, sin embargo, la formación de un ministro de la Palabra nos coloca frente al desafío de ser responsables de la fe de los demás; de ser testimonio y guía para la fe del pueblo. De ahí la necesidad de alimentarla. Ahora bien, ¿cómo alimentarla? ¿cómo encontrar los ámbitos e instrumentos de este alimento diario? ¿cómo instrumentarlos desde el Seminario?

En el ejercicio del ministerio entendido todo como servicio (sacramental, magisterial, de guía). Se necesita superar cierta mentalidad, reductiva y sin sentido, según la cual el servicio sacerdotal al pueblo de Dios se convierte en una burocracia religiosa y cumplimiento rutinario de un rol sagrado. Si es así, o se va a la deriva o se busca en otra parte (en otras "espiritualidades" o modalidades, que, en el mejor de los casos, resultan ajenas a la propia vocación específica) el necesario alimento de la fe.

Familiaridad personal con la Palabra de Dios. No hablo de lectura-estudio de la Palabra (necesaria por otra parte), sino le lectura-oración. Oración y docilidad a la Palabra para hacerla penetrar, hasta el interior, hasta el campo profundo de las propias elecciones con el fin

Mostrar una fe fuerte, sin ocultar las dificultades que entraña 
162

Oír con

asiduidad

la Palabra

como ora-

ción aco-

gedora
Experiencia de fe en lo concreto de las situaciones de purificarlas y conformarlas al Evangelio. Saber oírla (Rom. 10,17) ya que nuestro mundo interior tiende, inevitablemente, a orientarse en la dirección de aquello que entra con asiduidad y es acogido con activa y profunda atención. ¿Qué pasaría en la fe de un sacerdote si éste se decidiera a dedicar al estudio amoroso y a la lectura "orante" de la Palabra, al menos la misma energía que, en tiempo y "participación" afectiva, dedica a la (también útil) lectura de los diarios y a los noticieros televisivos?

El sacerdote experto en ejercitar la fe. El ejercicio de la fe es muy necesario para enfrentar tres fenómenos actuales: la pereza pusilánime de quien pide al Señor siempre y sólo signos inequívocos y extraordinarios; la mentalidad pagano/farisaica de quien, con el solo buen sentido religioso, tiene todas las respuestas a todos los problemas porque ha reducido la fe a un códice de instrucciones; el extravío y la desesperación de quien, viendo la seriedad que comporta ser creyente, se bloquea frente a las primeras dificultades y prefiere la derrota de su fe. Sólo un experto en navegación de estos mares procelosos, puede ayudar, servir eficazmente, a quien casi naufraga en alguna de las direcciones señaladas. Ese servicio se espera, con derecho de los fieles, del sacerdote. A ese servicio no se accede con la ordenación sacerdotal. No es suficiente la opción de fe, sino la experiencia de la fe en lo concreto de las situaciones. La práctica en ese ejercicio de fe se inicia en el Seminario.

\section{3.- SUGERENCIAS}

El Seminario es concebido como una escuela creativa en relación al servicio. Se han de buscar estrategias de capacitación para influir en una comunidad en vistas a su trasformación, es decir, lograr hacer una comunidad evangelizada y evangelizadora. El servicio a la comunidad es el legítimo móvil, pero habrá que estar atentos y dar consistencia al mencionado móvil, mediante un serio trabajo intelectual, dentro del Seminario, para poder 'tomar el pulso', objetivamente, a la comunidad.

Tocar la realidad del pueblo, en la Diócesis, no significa lanzar a los jóvenes seminaristas, apenas entran en el Seminario, a experiencias 
de pastoral, sin las "armas" adecuadas para que a ellos le sirvan tales prácticas pastorales y, al mismo tiempo, con ellas ofrezcan algún servicio bueno al pueblo. Acertar en el discernimiento sobre el caminar de la comunidad es su servicio valioso que da forma a la espiritualidad del clero diocesano, y esto hay que iniciarlo desde el Seminario, tomando todas las medidas con inteligencia, prudencia y paciencia. No se vale la precipitación o la improvisación, so pena de abortar lo que podría ser muy viable o de coger vicios difícilmente erradicables. Por otro lado se ha de tener la valentía necesaria para superar miedos ante lo desconocido; para infundir una mentalidad según la cual la formación al presbiterado exige un nuevo estilo de vida polarizado por la decisión de servir a la Palabra y al Pueblo.

El Seminario seguirá siendo un lugar privilegiado para descubrir la identidad más profunda del propio ser-llamado-para-lamisión. Es la base que apoyará la conciencia de la propia dignidad y que logrará la obtención de una fuerza capaz de superar los propios límites. Se trata de una capacitación profesional, permanentemente trabajada, en solidaridad ejemplar con la comunidad del Seminario y con la comunidad presbiteral. Aquí radica el secreto del cuidado y atención a la Palabra para servir al Pueblo.

La alegría y gusto por conocer más, encuentra su centro de inspiración en la mística del servicio. Es interesante despertar un fuerte entusiasmo por descubrir formas nuevas de crecimiento personal y comunitario; es muy fácil renunciar al crecimiento, lo que se da cuando uno ya se siente bien con la propia estatura. Sería interesante analizar el fenómeno, ampliamente constatado, según el cual un joven recién ordenado presbítero, ya se siente pleno, acabado, formado...

El desarrollo de la capacidad contemplativa no es un "algo de lujo" para un presbítero diocesano. En el centro del discurso formativo para el servicio está el discurso sobre la verdad-bondad, que, para comprenderlas en plenitud, deben antes contemplarse y así puedan convertirse en fuerza que impulse a la superación. El estudio profundo, sistemático, fundamental, ordenado, en las aulas, con método científico... es el mejor instrumento para la búsqueda de elementos concretos, constatables y eficaces, en orden a la 'inculturación' del mensaje; exige un comportamiento de reacción fuerte, frente a los nuevos desafíos de la sociedad actual. Para lograrlo no hay otras armas que las del

Estudio, instrumento para la 'inculturación' del mensaje 
diálogo y 'narración' testimoniada con la vida. Este es el servicio sacrificado más valioso de un Pastor.

En el Seminario se agudiza la conciencia de las responsabilidades dentro de la Iglesia. Es necesaria la fantasía para pasar de la teoría a la convicción operante de que 'en la Iglesia todos somos responsables'. En el Seminario se vive en esfuerzo permanente y en tensión por articular y organizar a toda la comunidad concreta. Los jóvenes llegan al Seminario con una vida desorientada, con mentalidad individualista y pragmática, sin valores radicales apasionantes, sin grandes ideales... de ahí que la vida común y solidaria sea tan importante; ha de tener como centro a la persona y no tanto las ventajas afectivas y prácticas de la vida común y de la solidaridad.

$\mathrm{El}$ amor incondicional a todos, con preferencia a los hermanos más necesitados, en lo concreto de la vida en el Seminario o dentro del presbiterio, es el mejor estímulo para mantener la opción fundamental

Amor incondicional, estímulo para opción de servicio al Pueblo por el servicio al Pueblo. Esto es posible si se practica una experiencia fuerte de Dios como Padre común, y de Iglesia como madre acogedora y liberadora. Es necesario formar en la conciencia de la dignidad y de la igualdad de todos, porque todos somos hijos de Dios. El Evangelio tiene capacidad para superar toda soledad egoísta.

En el Seminario se han de integrar las etapas, las dimensiones, los procesos personales y comunitarios para lograr ser. Formar para ser hombre-cristiano-sacerdote (formación humana, espiritual y pastoral), es el desafío permanente para quienes han optado por el Servicio a la Palabra y al Pueblo. El ser persona reclama a una comunidad, porque ésta es, irrenunciablemente, el espacio coherente, generador de actitudes para 'ser más'. Ser, ser-hombre-cristiano-sacerdote, en su más profunda realidad, es ser para los demás. Lo más hondo de este ser está vinculado a la dimensión de servicio a la comunidad.

Todo quehacer formativo en tal sentido ha de generar alegría, felicidad profunda y satisfacción en el trabajo propio formativo ya que está en juego la realización y proyección del propio ser. La realización personal es condición para actuar en clave de ser-para-el-servicio y da capacidad para caminar junto a aquellos (los hermanos), mismos que dan razón de su propio ser. 


\section{SEGUNDO ÁNGULO: LA COMUNIÓN}

\section{1.- VALOR SELECCIONADO: PERSONA Y COMUNIDAD}

Creer en un solo Dios, en un único Mediador y en un solo Espíritu, es también aceptar y vivir un solo bautismo y una sola eucaristía. La unidad de la Iglesia es significada y edificada es sus sacramentos; ella es sacramento, signo e instrumento de unidad y reconciliación, de paz entre los hombres, las naciones, las clases y los pueblos.

La unidad de fe y sacramentos, lleva necesariamente a la unidad jerárquica, especialmente con el centro de la unidad, que Cristo ha dado a su Iglesia en el ministerio petrino (LG 9). La comunión eclesial con Pedro y con sus sucesores no es obstáculo sino anticipación y signo profético de la unidad plena.

Por otra parte, el mismo y único Espíritu actúa con muchos y variados dones espirituales y carismas (I Cor. 12, 4). La única y universal Iglesia está presente, verdaderamente, en todas las Iglesias particulares (CD 11). Éstas están formadas a imagen de la Iglesia universal de tal modo que la una y única Iglesia católica existe en y a través de las Iglesias particulares (LG 23). Tocamos aquí el verdadero principio teológico de la variedad y de la pluriformidad en la unidad, pero es necesario distinguir la pluriformidad del puro pluralismo. "Cuando la pluriformidad es verdadera riqueza y lleva consigo la plenitud, ésta es verdadera catolicidad. Al contrario el pluralismo de posiciones fundamentalmente opuestas lleva a la disolución, destrucción y pérdida de identidad" (Sínodo 1985, No. 1801).

Si la Iglesia es comunión debe haber participación y corresponsabilidad en todos sus grados. Este es un principio general y deberá entenderse de distintas maneras según los diversos ambientes.

Entre el Obispo y su presbítero existe una relación fundada en el sacramento del orden. Los presbíteros hacen presente, en cierto sentido, al Obispo y asumen, en la pastoral cotidiana directa, las tareas y solicitud pastoral de aquel (LG 28). En consecuencia, las relaciones entre el Obispo y sus presbíteros han de ser amigables y de total confianza; se imponen la cercanía, la ayuda mutua, la colaboración, el sostén...

La comunión se inspira en principios (y los hay, de gran riqueza teológica), pero se expresas en realidades concretas en las que hay que 
educarnos permanentemente. Propongo una que puede ser catalizadora en la formación seminarística y unificadora en la vida sacerdotal: la comunión interpersonal a nivel de profundidad espiritual.

Para alcanzar este centro interior de comunión, base de la comu-

Centro interior de comunión: la comunión interpersonal espiritual nión sacramental en la Iglesia a todos los niveles, es necesario recorrer un cierto itinerario. Se trata de formas y experiencias concretas, de alto valor formativo en todo aquello que diga referencia a la comunión. Se valora lo interpersonal en dimensión y clave espiritual. Es un camino posible para "experienciar" la comunión interpersonal eclesial.

Oración comunitaria. La Palabra viva se hace presencia de Cristo (SC 7); el Espíritu de Dios congrega en la unidad y se vuelve señal eficaz de comunión de unos con otros (I Jn. 1, 1-3). ¿cómo nos interpela la Palabra, para nuestra salvación? ¿qué respuestas de fe provoca en nosotros?

Comunicación de vida. Los dones del Espíritu son para la edificación del cuerpo (Ef. 4, 7-16). Descubrir los dones propios, que son dados en orden a la comunidad, es una seria responsabilidad. La diversidad de dones (I Cor. 12,11) es obra del mismo Espíritu y éste permite, superando envidias, descubrir, reconocer, aceptar y hacer crecer los dones de los demás. En esta actitud "se realiza la unión de la verdad con la caridad, de la inteligencia con el amor..., se descubre cómo son diversos los caminos que conducen a la luz de la fe y cómo es posible hacerlos converger para un mismo fin" (ES, 76 y 77).

Revisión de vida apostólica de la comunidad. Los procesos inacabados de formación comprueban que somos peregrinos en el tiempo; caminamos entre luces, penumbras y oscuridades y por ello necesitamos, permanentemente, de revisión, conversión y renovación. Es necesario verificar el servicio mutuo para el crecimiento del Reino. Vivir la verdad en la caridad hace crecer al cuerpo cuya cabeza es Cristo (Ef. $4,13)$. Ver tareas comunes, evaluar su eficacia, analizar causas, proyectar acciones futuras, con este "espíritu", es lo mismo que ver y tocar la comunión en la Iglesia. 
Revisión de la vida comunitaria. La construcción de la comunidad según el plan de Dios forma parte de lo esencial de la vida cristiana (Jn. 17, 20-26), como la Iglesia lo comprendió desde el principio (Hech. 2, 42-47; 4, 32-37). De aquí la responsabilidad de una revisión comprometida sobre el modo concreto como estamos viviendo esta dimensión de la fe. Se abre una veta importante para la educación al diálogo profundo, puesto que aquí no se trata de la mera utilización de técnicas y dinámicas de grupo sino de confrontación con el Evangelio, traducido en documentos eclesiales, constituciones, etc.

Promoción fraterna comunitaria. Es una forma de encuentro, según el espíritu del Evangelio, para servir al crecimiento de las personas y de la comunidad, mediante la ayuda mutua en el desarrollo de las cualidades y en la superación de los límites. Mt. 18, 15-17 sugiere un fundamento de esta promoción: el precepto del servicio a los más pequeños y el perdón sin límites; la condenación del escándalo y de la falta de misericordia; la certeza del valor de la oración comunitaria y de la presencia de Jesús en medio de los que se reúnen en su nombre. De este modo el compromiso permanente en el crecimiento del hermano, expresado en forma concreta, es de hecho una exigencia evangélica propia de una comunidad cuyos miembros quieren vivir el misterio de la comunión con Cristo, de tal modo que aceptan pagar el precio de esa comunión, pasando por la cruz de la purificación, decididos a crecer en Él hasta la plenitud de la madurez. Es la aplicación, personal y comunitaria, de I Cor. 13.

\section{2.- LINEAS INSPIRADORAS}

La formación es transformación de la persona, pero el dinamismo interno de la acción formativa tiene un horizonte: la integralidad, y tiene un espacio: la comunidad del seminario o el presbiterio.

1.- La formación comunitaria, en, para y con la comunidad, no es formación masificada; al contrario es altamente personalizada. La sociedad actual tiene muchos signos de masificación, despersonalización, uniformismo, anonimato y ejerce grande influencia en los jóvenes de hoy. En no pocos ambientes existe la tentación de aplicar un

Formación comunitaria personalizada

Compromi so permanente en el crecimiento del hermano 
mismo molde educativo a todos los formandos; se argumenta diciendo que es necesaria la unidad en la formación de los presbíteros y que se impone un cierto estilo parecido entre los sacerdotes de una misma Diócesis.

La verdad es que Dios llama a personas concretas y con nombre propio. Jesús escogió personalmente a sus apóstoles y personalmente les invitó: "sígueme". Los reunió en un grupo pero trató a cada uno de ellos de modo personal, específico; se adaptó a la variedad de temperamentos de cada uno de ellos, los trató de modo diverso, tuvo para cada uno de ellos, un plan distinto, personalizado. Lo anterior tiene que dar líneas para resolver los problemas de grandes seminarios (en México, p.ej. hay unos 12 Seminarios Mayores con una población de 200 a 500 jóvenes). Se necesita creatividad, fantasía e iniciativas ponderadas para no renunciar a una formación personalizada.

2.- Si la vocación procede de la libertad amorosa de Dios y por ello es gratuita, la respuesta del hombre también es libre y personal;

El camino de respuesta tendrá que ser personal por ello tendrá que ser personal el camino de su realización. El joven que se siente tratado como un número anónimo perdido en la masa, no tiene motivos para promoverse y esforzarse por la autosuperación; por el contrario la atención personal estimula y promueve. La formación auténtica ha de tener en cuenta a cada persona en singular, cada hombre como individuo único e irrepetible.

Estoy convencido que el acompañamiento personalizado, en los procesos graduales de discernimiento, consolidación y vivencia de la vocación sacerdotal, es el más grande reto que hoy se pone a los formadores de un Seminario y a un Obispo para con su presbiterio. Se ha estudiado mucho el tema del acompañamiento personalizado, suele ser la prueba de fuego para juzgar la calidad de un formador. A éstos se les piden grandes sacrificios no siempre apreciados o reconocidos, ni en el seminario ni en el presbiterio. Por otra parte se trata de un conjunto de "armas formativas" no fácil de conjuntar en un formador y la tentación es grande: querer cualquier trabajo, pero fuera del Seminario. Efectivamente, puede costar la vida caminar con (ni tan adelante que aparezca extraño y distante, ni detrás como si fuera un simple vigilante) el formando, pero ahí, precisamente, se gana. Es el ejercicio concreto de la paternidad con entrañas de amor paciente que espera siempre. 
3.- La formación personalizada significa también que todos los formadores (en este apartado incide la importancia del Equipo de los Formadores) conocen personalmente a los seminaristas. La relación entre formandos y formadores es cordial y cercana. No basta conocer, hay que interesarse efectivamente, todos por cada uno, en lo que realmente trae el joven por dentro: necesidades, problemas, gustos, inquietudes, proyectos... Por tal interés se le sigue de cerca al joven, se analizan con él sus situaciones y procesos formativos. Así se puede tener capacidad para adaptar a cada uno, los principios y directrices de la formación. Hay que estar atentos a no absolutizar los programas globales sino, más bien, saber adaptarlos a los ritmos de cada uno. Esto exigirá una buena dosis de flexibilidad y prudencia.

Formación personalizada y comunitaria. Pueden parecer términos contrapuestos. No es así, hay que entenderlos bien; pero sí están en tensión permanente. No hay verdadero desarrollo y realización de la persona si no es en la apertura dialogal y en la convivencia cordial con los demás. No hay verdadera comunidad de personas si cada uno de sus miembros no se realiza a sí mismo en cuanto persona. Se ocupa una buena dosis de espiritualidad para descubrir la belleza de la comunidad, sin renunciar a la identidad personal; digo que es cuestión espiritual porque, en medio, hay mucha cruz. Significa renunciar al individualismo, a lo solitario, al capricho, al egoísmo y abrazar a los otros en el desasimiento sacrificado y en el exigente amor de quien ha hecho de su vida un proyecto de donación total.

4.- Se reafirma la validez del Seminario como ambiente comunitario eclesial que vive el ideal de la formación para el sacerdocio, como servicio a la Iglesia y al mundo. Esta comunidad es necesaria (ordinariamente) para la eficacia real de la formación del futuro sacerdote. Jesús mismo los llama por su nombre pero los reúne en grupo para formarlos en común. Los "doce" no indican sólo la suma de doce personas sino una comunidad de vida en torno al Maestro.

Por otra parte, el sacerdocio tiene sentido únicamente dentro de la Iglesia en cuanto pueblo de Dios, comunidad de creyentes. El candidato al sacerdocio tiene que experimentar y vivir el sentido de comunión que es, más que una categoría teológica, una realidad vital. Todo pastor ha de ser guía y fermento de una comunidad. El sacerdote diocesano

Saber adap-

tar los programas a los ritmos de cada uno 
está en medio para promover y acompañar a las personas con sus carismas, dentro de la comunidad parroquial o diocesana. Ahí está, muchas veces, el drama. El sacerdote diocesano tiene que conocer y acompañar los dones y ministerios que el Espíritu Santo va regalando a la comunidad; ha de saber coordinarlos y armonizarlos de tal manera que se pon-

Sacerdote acompañante de la comunidad, coordinador de los dones gan al servicio de todos, a pesar de que, no pocas veces, suelen darse antagonismos, luchas estériles, cansancio, desilusión, competencias desleales, confrontaciones sin sentido y hasta luchas al interior de la comunidad. Quiere decir que todavía no se ha experimentado y amado lo que es comunidad, comunitario, comunión. ¿Cómo se puede transmitir el sentido comunitario a los fieles si el sacerdote no ha vivido en primera persona, la belleza de la comunidad y de la comunión?

5.- Quizá haya que seguir favoreciendo experiencias de presbíteros que adoptan algún modo de vida en común, conforme lo recomendó el Vat. II (CD 30 y PO 8). Efectivamente, la vida comunitaria aporta elementos de vital importancia en la formación permanente del sacerdote. No sólo es oportunidad de servir sino espacio de diálogo y de apertura a los demás, permanente conocimiento y comprensión de necesidades de los demás, posibilidad de partir el pan y compartir los bienes materiales o espirituales, invitación suave y constante a salir de sí mismo, a servir, a donarse gratuitamente. El apoyo de un ambiente sano, hoy, tiene mucha importancia porque se multiplican, al lado nuestro, los ambientes insanos; son importantes los procesos de crecimiento espiritual, el testimonio vivo de los demás y palpado por mí, en primera persona. El estímulo de los compañeros puede ser decisivo para sostener el esfuerzo en el trabajo y para la perseverancia gozosa en la vocación.

\section{3.- SUGERENCIAS}

Si algo es un Seminario o un Presbiterio es "comunidad fraterna". Hay una grave y permanente responsabilidad en sus miembros para construir día a día la fraternidad como experiencia novedosa. Se ocupa una 'forma mentis' una 'infraestructura' y una 'experiencia concreta'. Para construir la comunidad es necesaria la participación concreta en la vida de la comunidad, participación solidaria y responsable en el tejido complejo de las múltiples expresiones de la comunidad. Es 
importante saber crear un 'clima' de paz y de unidad. No se puede olvidar la necesidad de la acogida sincera, respetuosa y digna del otro, tal cual es. Hay que prestar mucha atención a los desafíos de los 'grupos internos' en la comunidad con mentalidad 'farisaica'; aunque también los puede haber con mentalidad demasiado permisiva: los costos en las divisiones internas de un Seminario o Presbiterio son demasiado elevados y más que construir, destruyen o, por lo menos, desgastan inútilmente. Es posible la rotación de servicios y responsabilidad para no crear monopolios divisorios. Es bueno mantener el esfuerzo por identificar valores vividos comunitariamente y estimular con los mismos a la propia comunidad. Finalmente, si un seminarista no adquiere la capacidad de vida comunitaria, trabajo en equipo, gusto por buscar a toda costa la comunión en sus grupos de pertenencia, es un signo claro que no es para el presbiterado.

Para lograr lo anterior se necesita desarrollar una actitud de amor y desprendimiento hacia los demás miembros de la comunidad de referencia y vida concretas, sobre todo hacia los más necesitados. En la medida que haya conciencia de la aceptación propia y del otro (en cuanto personas) se puede esperar que la comunidad sea el espacio y la fuente de crecimiento espiritual serio. Lo que permite actuar con alegría y entusiasmo, y por lo tanto plenificante para la persona, es la referencia comunitaria. Se cumple el ejercicio de autoridad, en la comunidad, con profundo sentido de servicio, con amor y respeto a los procesos de crecimiento de los demás.

La vida de comunidad está orientada al reconocimiento de sus miembros como hermanos que caminan juntos hacia una meta común: ser hombres auténticos y libres, capaces de transmitir su experiencia como algo valioso. Conocer las propias potencialidades, valores y límites, es fuente de estabilidad psicológica y de esperanza. La eclesiología del Vaticano II y los profundos retos actuales puestos a la comunidad de la Iglesia, para la evangelización de la cultura y la civilización del amor, no dejarán de ser "ideales" si no se cuenta con una pléyade de presbíteros, en las bases diocesanas, con un profundo sentido de comunión y comunitariedad.

Al interiorizar la experiencia de comunión y de comunitariedad, se conocen bien los retos y situaciones que hoy se plantean a la vida

Desarrollar actitud de amor hacia los miembros de la comunidad 
cristiana y a la experiencia sacerdotal y, en la medida de lo anterior, se generará una conciencia de las exigencias de lucha y compromiso contra las injusticias. Al conocerse mejor a sí mismo y a los demás, se descubrirán valores insospechados $\mathrm{y}$, en consecuencia, una activación orgánica de los mismos con la evidente potencialización de las personas y las comunidades. Se conocen los errores y se juzgan las situaciones de pecado social y, a la luz del Evangelio, se ofrecen respuestas adecuadas.

No se puede olvidar la urgencia de 'vivir junto a'. Es fuente de aprendizajes constantes y superación de 'soledades' estériles y peligrosas. Desafía mucho a los intereses particulares, pero fecunda en gran medida la interioridad de vida personal y potencia la acción pas-

Aquí ven-

drá un resumen del párrafo toral en la comunidad. Cada uno es valioso en la comunidad; con ello se constata la bondad de espacios de libertad y comprensión. Se puede desarrollar un profundo amor a la vida y los bienes materiales se ponen al servicio común. Todas las reservas personales o comunitarias (ahorros, especializaciones, capacitaciones), se ponen al servicio de todos.

Si hablamos de opción preferencial por los pobres y necesitados, nunca será posible vivirla si no hay sentido de compasión por el menor, por la solidaridad generosa hacia quien sufre, concretamente, en la propia comunidad. La espiritualidad se enriquece enormemente cuando se descubre y practica el valor de la donación personal, bajo el estilo práctico de búsqueda de caminos que contribuyan al bien común como patrimonio de todos. La impostación de la pobreza, del presbítero diocesano debe asumir estos caminos.

La vivencia de los valores evangélicos se ha de expresar con gran nitidez; incluso los de fuera se han de sentir atraídos por ese 'ser profundo' de la comunidad. Se adquiere capacidad de acogida a los alejados porque se vive en coherencia con el ser propio: paz, fraternidad, comunión, unidad, respeto, reconciliación..

Se es más en la medida que haya convicción profunda de la eficacia del evangelio en la propia vida; así se adquirirá y desarrollará un sentimiento de seguridad y los límites personales pasarán a ser un reto y no un motivo de depresión personal o de tensión inútil en la comunidad. La actuación de la persona será segura y responsable en la medida que haya conciencia de que el propio trabajo contribuye al crecimiento comunitario. 


\section{TERCER ÁNGULO: EL TESTIMONIO}

\section{1.- VALOR SELECCIONADO: LA FIDELIDAD}

Un elemento destacado en la espiritualidad del sacerdote diocesano es la capacidad testimonial de fidelidad.

Fidelidad al propio sacerdocio como adhesión inquebrantable al concepto y la forma de un sacerdocio como participación del sacerdocio de Cristo. Fidelidad al ser sacerdote como Cristo, es lo mismo que comprometerse vitalmente al estilo de Cristo; aún más, es ser El, ser prolongación, presencia y acción de Cristo Sacerdote, de tal manera que las palabras del sacerdote son resonancia de las palabras de Cristo; los pensamientos del sacerdote no son exposiciones "luminosas" del propio sacerdote, sino pensamientos de Cristo; los sentimientos y actitudes del sacerdote son los de Cristo. Se trata de una exigente congruencia entre la persona y vida del sacerdote con la persona y vida de Cristo. El camino para no perderse en esta asunción y empeño, es el Evangelio mismo y la respetuosa y religiosa adhesión al Magisterio de la Iglesia. Esta es la más exigente fidelidad a la identidad sacerdotal clara, definida y sin ambigüedades.

Pero también se requiere fidelidad a la Iglesia. No a una Iglesia vaga, amorfa y abstracta, sino a la Iglesia concreta, viva, realizada en un tiempo y en un lugar determinado. El telón de fondo teológico es la sacramentalidad de la Iglesia (LG 1). Ser fieles a la Iglesia es tener una actitud de adhesión obsequiosa de pensamiento y de corazón con su magisterio, con sus instituciones, con sus disposiciones, con las personas: el Papa y los Obispos, como garantes de la comunión eclesial y de la apostolicidad de la iglesia; los hermanos presbíteros como miembros del "cuerpo presbiteral" concretísimo, con rostro claramente identificado y perfiles de grandezas y pequeñeces al alcance de la diocesaneidad; los laicos en su policromía de carismas, situaciones, etc... a quienes se debe totalmente, con las inevitables tensiones (riquezas y limitaciones) de quien ha de conocer a todos sin poder dar respuestas especializadas a todos, alentar pluralidad de carismas sin identificarse, quizá, con más de alguno...

Pensamiento del sacerdote, no experiencias "luminosas" propias, sino de Cristo 
Iglesia diocesana, esposa concreta del sacerdote diocesano
La Fidelidad a esta Iglesia exige sí, la adhesión obsequiosa, pero también afectuosa y razonada. La adhesión a la Diócesis como concreción y presencia viva de la Iglesia, se hace más pura y genuina, en la medida que se experimente la condición esponsal. La Iglesia diocesana es la esposa concreta del sacerdote diocesano. Se abre, así, para él, un constante desafío comunional en pensamientos, voluntades, acciones, propósitos, afectos:

¿Cómo mantener la ilusión de los primeros años? ¿Por qué decae el vigor espiritual, cuando se va constantando que la "esposa" no es lo que se sueña en el "noviazgo"?

¿Cómo legitimar, razonablemente, la credibilidad si no se da armonía suficiente en los significantes? ¿Cómo se puede liberar un sacerdote del ámbito subjetivo, en el terreno de la credibilidad, si no ve que los signos concretos de Evangelio en su propia realidad, no sólo no le conducen al sentido sino que le opacan la verdad misma?

¿Se puede pretender que la historia demasiado concreta y a veces hasta escandalosa, de la Iglesia diocesana, muestre la acción de Dios? ¿Las divisiones entre movimientos laicales, grupos de fieles (al interior de la misma parroquia), o de los presbíteros en la misma Diócesis, no llevan a creer que en la institución se actúa y se decide, en su operar histórico, en dependencia de circunstancias concretas, como en cualquiera otra de las instituciones del mundo?

La comunión afectiva y efectiva empieza por el Obispo, representante principal de Cristo en la Diócesis; se hace adhesión fraterna y obsequiosa con los hermanos sacerdotes; se traduce en afecto y servicio solícito y diligente, abnegado y generoso a los fieles. Una comunión así se hace celo misionero, que impulsa a ir por las plazas y caminos a donde están los alejados de Dios, los indiferentes, los ignorantes, los hostiles y agresivos. Esa es la fidelidad a la Iglesia y a la misión recibida.

Fidelidad al ser de pastor. No se trata de ser un pastor cualquiera y menos un pastor descuidado, indolente, perezoso, distraído, al que el lobo le arrebate las ovejas, sino pastor al estilo del Buen Pastor, Cristo Jesús. La fidelidad a Cristo y a su Iglesia nos lleva, como consecuencia, a la fidelidad a los hombres concretos de nuestro tiempo y de nuestra tierra. Por eso no podríamos ser eficaces y acertados en la pas- 
toral si trabajáramos a ojos cerrados, desconocedores de las realidades y necesidades, de los problemas y aspiraciones de los hombres de hoy, especialmente de quienes nos han sido confiados. "Por ello debemos procurar abrirnos en la medida de lo posible a la iluminación superior del Espiritu Santo, para descubrir las orientaciones de la sociedad moderna, reconocer las necesidades espirituales más profundas, determinar las tareas concretas más importantes, los métodos pastorales que habrá qué adoptar, y así responder de manera adecuada a las esperanzas humanas" (PDV, 5).

De la conciencia clara, de la convicción profunda de que Dios nos ha llamado, nos ha ungido y nos ha enviado, no a una misión particular, personal, sino a realizar y continuar la misma misión de Cristo, surge la exigencia, en nosotros, de ser fieles a esa misión. Fidelidad que nos debe llevar a tener siempre la mirada atenta a los signos de los tiempos, a la situación cambiante de la sociedad en que se desarrolla la misión, a elaborar planes y proyectos de acción pastoral que respondan a las necesidades concretas de la comunidad que se nos ha asignado dentro de la Diócesis.

\section{2.- LINEAS INSPIRADORAS}

1) El sacerdote es testigo del hombre: tiene sentido ser hombre. Cristo "manifiesta plenamente el hombre al propio hombre y le descubre la sublimidad de su vocación" (GS 22). Él es el hombre perfecto que ha devuelto a Adán la semejanza divina, deformada por el pecado. En su naturaleza humana, libre de todo pecado y asumida en la Persona divina del Verbo, la naturaleza común a todo ser humano viene elevada a una altísima dignidad: el Hijo de Dios por su encarnación "pensó con inteligencia de hombre, obró con voluntad de hombre, amó con corazón de hombre". Al hacerse hombre perfecto "se ha unido en cierto modo con todo hombre" (GS 22). Este es el misterio de Cristo: testigo de la humanidad redimida. Este es, así mismo, el misterio del sacerdote: ser testigo de la capacidad de respuesta humana al amor de Dios. La condición sacerdotal es una condición testimonial del amor de Dios, en Cristo, al hombre. El sacerdote, hoy, tiene que dar sentido, mediante signos inteligibles para el hombre actual, al hecho mismo de ser hombre.

Sacerdote, testigo de la humanidad redimida 
2) El sacerdote es testigo de valores. En el ámbito cultural profundo, en relación a valores de orden metafísico y moral, de la verdad y del bien, hay que confesar, con pena, que pasamos por una crisis de la inteligencia y de la libertad. La voluntad se independiza de la norma y la inteligencia se siente débil en el esfuerzo necesario de la búsqueda de la verdad. Hay crisis sociales, económicas, políticas, etc., porque hay crisis de valores como p.ej. un profundo oscurecimiento del sentido último de la vida. El sacerdote, hoy, en este terreno axiológico, juega un papel muy importante. El sacerdote es uno de los agentes sociales que puede rescatar mejor el sentido de la vida, con la condición que dé un claro testimonio del valor que entraña. Es responsabilidad del sacerdote hacer que el rostro de Dios, que brilla con todo su esplendor en el rostro de Cristo, brille también en el rostro humano, sobre todo en el rostro de los más golpeados en la sociedad, para que la verdad del Evangelio sea testimoniada a plenitud. El eclipse de Dios, significa el eclipse del hombre. Si se pierde el sentido de la existencia de las personas, si carece de sentido la historia de la sociedad, la conciencia pierde unidad y vive de fragmentos empíricos, transitorios, lle-

Testigo de unidad y de armonía

Propuestas concretas $y$ exigentes de santidad vando a una cultura del fragmento, que desconoce la belleza de la unidad y de la armonía. Por ello el sacerdote es testigo de la unidad y de la armonía en donde resplandece el misterio de Dios.

3) El sacerdote es testigo de viaje por itinerarios progresivos de santidad. ¿"Qué tengo que hacer para alcanzar la vida eterna"? (Mc. 10,17). Los jóvenes escuchan y siguen al Papa porque es exigente con ellos: "no tengan miedo de ser santos" "vuelen a gran altura". Los jóvenes de hoy tienen hambre y sed de Dios, de justicia verdadera y de santidad. Tienen deseos de orar y buscan en los sacerdotes "maestros de oración" "Señor, enséñanos a orar" (Lc. 11,1). En el camino de la formación hacen falta propuestas concretas y exigentes de santidad. La comodidad y superficialidad no es lo que buscan, en serio, los jóvenes. Un seminario blando en todo, que se maneja con los criterios de la facilidad, del gusto, del confort, no es atractivo. Tampoco se trata de volver a las disciplinas militarescas de otros tiempos; estoy convencido que los jóvenes en el Seminario (y se dará su reflejo en los presbíteros en la Diócesis) son capaces de amar la pobreza y la cruz, el desierto y la oración, la justicia y la caridad, el servicio y la 
solidaridad, con tal que vean testigos concretos en el viaje hacia las exigencias gozosas de las bienaventuranzas.

4) El sacerdote es testigo y signo de la caridad del Buen Pastor y "signo de la prioridad absoluta y gratuidad de la gracia que Cristo resucitado ha dado a su Iglesia" (PDV 16). Para poder testimoniar la caridad pastoral la persona del seminarista (sacerdote) y la comunidad del seminario (del presbiterio) se han de poner a tono con las urgentes exigencias evangelizadoras, a cuyo terreno no entro aquí porque se han dicho en muchos lados. Para evangelizar eficazmente es absolutamente necesario organizar la vida personal y comunitaria:

- en una línea de oración y estudio (como base del ministerio profético del anuncio); la oración y estudio deberán desembocar progresivamente en un ministerio testimonial-profético para seguir "inculturando" adecuadamente el Evangelio de siempre, con profunda sensibilidad a las situaciones y culturas propias del pueblo y, al mismo tiempo, con generosa atención para custodiar y valorar la unidad de la fe, la integridad y fidelidad a la doctrina católica;

- en una línea de fraternidad y vida comunitaria (en relación con la Eucaristía como sacramento de unidad); el arte de ser "artífices de la unidad" (EN 77) no se aprende en libros sino en la práctica diaria del amor fraterno experimentado en el grupo primero de pertencia: el seminario y el presbiterio, ambos ambientes en los que existen roles y servicios diferenciados entre los miembros que los componen.

- en una línea de servicio incondicional sin privilegios (en relación a los demás ministerios sacramentales y de servicio de caridad).

El sacerdote sirve a la Iglesia misterio, comunión y misión. Este servicio sólo puede realizarse potenciando la realidad "comunión" del sacerdote como miembro del Presbiterio, presidido por el Obispo. Aquí se inscribe el basto campo de la formación a la obediencia y al ejercicio de la autoridad: terreno delicado y difícil que cuestiona constantemente a la comunidad del Seminario y al Presbiterio. Aprender a obedecer y a ejercer bien la autoridad es un importante desafío para la práctica de la caridad pastoral. Se trata no sólo de optar por la obediencia sino experimentarla como Jesús quien, "sufriendo, aprendió a obedecer..." (Heb. 5), y sólo así llegó a ser causa de salvación. 
5) Frente a las pruebas que exige el testimonio valiente, el sacerdote diocesano tiene que ser un hombre alegre y seguro; lo experimentará en la medida que perciba con claridad la certeza de la meta de su camino y viva la última razón de su entrega; el mensaje es buena

Hombre alegre, anuncia la buena nueva actual nueva actual; sabemos interpretar el paso de Dios en nuestra propia historia; somos capaces de juzgar la vida en coherencia a los valores que profesamos; tenemos la 'memoria' para mantenernos fieles a la Alianza, en relación con nuestro pasado y abiertos al futuro; nuestras opciones son por las causas justas. Normalmente se genera la convicción de colaboración en la realización de una misión divina; certeza del amor de Dios a su familia; promoción de diálogo respetuoso con quienes piensan de diferente manera; denuncia de lo que no está en consonancia con el hecho de ser Iglesia de Jesucristo (mentira, engaño, etc.).

\section{3.- SUGERENCIAS}

Es importante asumir una actitud permanente de búsqueda para hacer y 'rehacer', con creatividad permanente, la presentación de la Buena Nueva. Confesar, profesar, testimoniar, profetizar el paso liberador del Dios de Jesucristo, hoy, impone mucha atención al lenguaje, a los signos, a los símbolos e instrumentos para que éstos sean inteligibles al hombre de hoy. Las diversidades culturales, las categorías conceptuales variadas son desafíos para los evangelizadores; por ello se impone buscar los medios eficaces para predicar el mensaje evangélico, para confesar y profesar la fe de la Iglesia. El Seminario ha de ofrecer, en este campo, al menos una introducción, a sabiendas de que, después de la ordenación queda el campo abierto al esfuerzo para "traducir" el mensaje al lenguaje de los tiempos actuales.

Se hace evidente la formación permanente integral de los sacerdotes, no sólo como 'aggiornamento' teológico, sino como condición de ministerialidad variada y plural de los laicos, en la perspectiva de la 'evangelización de la cultura'. La 'confesión' de la fe en el templo (predicación, catequesis, sacramentos), en la familia, en el mundo del trabajo, en la escuela, en la convivencia, etc. desde donde nace la exigencia, también, de especialización. Lugar privilegiado tiene aquí la Religiosidad Popular -tan rica en América Latina-, pues ésta puede considerarse como 'otros modos de vivir y presentar el Evangelio'. 
¿Cómo avivar el gozo y la satisfacción por los esfuerzos hechos en torno a la 'inculturación' como pruebas de que el Evangelio cabe en cualquier situación y cultura? ¿En los procesos formativos se está haciendo posible lo anterior? Será necesario tomar clara conciencia de que entrar por esos caminos es aceptar en serio la cruz; en la paciencia sacrificada se hace 'la confesión'; en la medida que sean acompañados los procesos de inculturación del Evangelio, siempre lentos, paulatinos y dolorosos como sucede en el crecimiento personal y comunitario: es una ley de toda educación seria.

Saber 'dar razón de nuestra esperanza', hoy, es de suma importancia (cfr. Fides et Ratio). No andamos a ciegas en el camino. Hay una VERDAD que tiene capacidad de iluminar todo (la Revelación). La iglesia que se percibe a sí misma no sólo como 'depositaria' de un mensaje de salvación sino también la mediación (cfr. teología de los signos y las mediaciones) para la mayor inteligencia y nuevas comprensiones de este depósito $\mathrm{y}$, por lo mismo, mayor posibilidad para vivir este mensaje salvífico. Estar abiertos a la esperanza cristiana implica también apertura a Dios Padre que ama a todos los hombres y constituye a Jesucristo como el único Salvador, quien, a la vez, envía al Espíritu Santo como animador del caminar del pueblo hacia la verdad plena y hacia la casa del mismo Padre (cfr. TMA).

La novedad del evangelio es la clave de interpretación de la vida. No sólo somos una comunidad social, de amistad y servicios, sino, con clave teológica, somos un pueblo-iglesia de Jesucristo: comunidad convocada y reunida en torno al Señor que tiene para nosotros un proyecto. Somos partícipes de una vida comunitaria no pragmática sino conformada por el amor. En cada persona, sobre todo en los sufrientes, se delinea con precisión el rostro de Cristo salvador. Somos sacramento del Reino, hermandad que vive la alegría de ser redimida por el Padre común.

\section{CONCLUSIÓN}

El evangelio vivido ha de permeabilizar la totalidad del hombrecristiano seminarista o sacerdote. Toda la vida estamos en proceso de ser hombres-cristianos-pastores, pero hay muestras de madurez constante que se expresan con los 'signos del Reino'.

Apertura de Dios Padre que ama a todos los hombres 
Un sacerdote tiene que ser un hombre feliz; ha de experimentar satisfacción por interiorizar los valores del Reino que lo impulsan a ser más; el Evangelio es mensaje que transforma y da capacidad de denunciar todo aquello que se oponga al Reino; la actuación testimonial de un sacerdote, hasta la sangre, es a la vez, realización personal y servicio comunitario; se impone la coherencia de vida entre lo que se proclama y lo que se vive. 